\title{
Manutenção centrada em confiabilidade: aplicação em motoredutores de transportadores de correias em uma refinaria de alumina
}

Herbert Ricardo Garcia Viana herbertviana@hotmail.com Universidade Federal do Rio Grande do Norte Instituição (UFRN), Natal, Rio Grande do Norte, Brasil

\section{Adeliane Marques}

adelianeengpro@gmail.com

Universidade Federal do Rio Grande do Norte Instituição (UFRN), Natal, Rio Grande do Norte, Brasil

\section{Samir Birani}

adelianeengpro@gmail.com

Hydro Alunorte, Barbacena, Pará, Brasil

Salomão Sena

adelianeengpro@gmail.com

Hydro Alunorte, Barbacena, Pará, Brasil

Gilberto Hirokazu Nobumasa adelianeengpro@gmail.com Hydro Alunorte, Barbacena, Pará, Brasil

\begin{abstract}
RESUMO
Este trabalho apresenta uma aplicação do estudo de Confiabilidade através da análise de dados e geração das curvas $R(t), F(t), f(t)$ e $\lambda(t)$, contemplando seu uso na base operacional da área de filtragem de hidrato de uma refinaria de alumina. Nele, busca-se dimensionar o grau de confiabilidade dos motoredutores do modelo KA87/T AM132S/M, utilizados no acionamento dos transportadores de correia do sistema de filtragem de hidrato. $O$ estudo de confiabilidade dos motoredutores KA87/T AM132S/M das correias transportadoras foi realizado através do software ProConf 2000. Através dos testes de aderência, percebe-se que a distribuição de Weibull descreve satifatoriamente a amostra de dados acerca as falhas do motoredutor, com valores de $\chi 2$ com nivel de seignificancia de 60,82\%, e com teste análitico de Kolmogorov-Smirnov (K-S) de 30\%. Obtém-se um tempo médio até o reparo ou MTTF (do inglês Mean Time to Failure) do motoredutor de 648,98 horas. Os valores de $\mathrm{t} 10$ e $\mathrm{t} 50$ que consistem nos limites de tempos em que $10 \%$ e $50 \%$ dos reparos ocorreram, ficaram em 31,71 horas e 352,58 horas, respectivamente. Para um intervalo de confiança de $95 \%$, o tempo médio até o reparo (MTTF) compreende valores entre 356,15 a 867,04 horas, foi verificado também que a taxa de falhas corresponde a curva da banheira, e que as principais falhas têm como origem o sistema de vedação do eixo de entrada do motoredutor, ao final indica-se a aplicação da Manutenção Centrada na Confiabilidade (MCC) para os equipamentos críticos da planta.
\end{abstract}

PALAVRAS-CHAVE: Confiabilidade. Refinaria de alumina. Manutenção. 


\section{INTRODUÇÃO}

A intensificação da produção aliada ao avanço tecnológico tornaram os parques industriais mais sensíveis às atividades de manutenção. Salonen e Bengtsson (2011) relatam que a manutenção representam um papel estratégico, em especial na indústria transformadora. Otani e Machado (2008) e Al-turki (2011) observam que a manutenção enquanto função estratégica das organizações afeta e é afetada por diversas áreas funcionais, onde atua em decisões em todos os níveis, sendo responsável direta pela disponibilidade dos ativos, o que influência nos resultados financeiros da empresa.

Manter-se competitivo no mercado exige traçar estratégias bem definidas e ousadas, buscando-se sempre a melhoria contínua dos processos. Exigindo mais do que nunca que o setor de manutenção seja tradado de forma estratégica, buscando-se sempre a aplicação de técnicas consideradas de classe mundial para se obter alta confiabilidade e disponibilidade da planta, com o menor custo de produção possível.

Para Fogliatto e Ribeiro (2009), existe uma relação direta entre manutenção e confiabilidade, onde a primeira se propõe a reduzir falhas ou restaurar o estado do equipamqnro, o que favorece a melhoria e confiabilidade de operação do sistema de produção Para minimizar os custos da não eficácia e elevar os níveis de atendimento juntos às operações, os departamentos de manutenção, buscam excelência dos seus serviços, aplicando as melhores práticas conhecidas de gerenciamento da manutenção, dentre as quais os estudos em confiabilidade se revelam de grande relevância (NASCIF, 2000).

Segundo Sellitto (2005), o conceito de confiabilidade foi introduzido na manutenção por um trabalho seminal sobre falhas em equipamentos eletrônicos de uso militar nos anos 1950, nos Estados Unidos da América. A tarefa foi conduzida por um grupo de estudos da Federal Aviation Administration, cujas conclusões reorientaram os procedimentos de manutenção até então vigentes: i) se um item não possui um modo predominante e característico de falha, revisões programadas afetam pouquíssimo o nível de confiabilidade do item; e ii) para muitos itens, a prática de manutenção preventiva não é eficaz.

Zaions (2003) observa que, a partir dos anos 1970, várias indústrias iniciam a manutenção centrada em confiabilidade para determinar as melhores políticas para gerenciar as funções dos itens físicos e para gerenciar as consequências de suas falhas.

Para a ABNT na norma brasileira NBR 5462-1994, item 2.2.6.4, a confiabilidade de um item é a probabilidade de que este desempenhe a função requerida, por um intervalo de tempo estabelecido, sob condições definidas de uso.

Para Al-turki (2011) e Raza, Muhammad; Majid (2016) a manutenção desempenha um papel relevante na vida útil do equipamentos, no aumento da disponibilidade, da produtividade, na qualidade, na otimização de tempo e espaço e nos custos das organizações. Relatam ainda que, no cenário industrial, é necessário a incorporação de elementos da confiabilidade às estratégias e operações a fim de aperfeiçoar as técnicas e melhorar o desempenho do setor de manutenção. 
Perante tal contexto o objetivo deste artigo é analisar a confiabilidade dos motoredutores dos transportadores de correias da área de filtração de semente fina e grossa de uma refinaria de alumina, por se tratar de uma área estratégica para empresa, uma vez que é responsável por garantir a produtividade e qualidade do produto. Os objetivos secundários são: (i) calcular as funções densidade da probabilidade de falha, $f(t)$, confiabilidade, $R(t)$, densidade acumulada de falha, $F(t)$, e taxa de falha, $\lambda(t)$; (ii) posicionar o equipamento no ciclo de vida (curva da banheira).

Observou-se na literatura similaridades em estudos desenvolvidos em vários ambientes industriais, desses, alguns contribuíram para este trabalho e podem ser citados. Cerveira e Sellitto (2015) definiram a estratégia de manutenção para um forno elétrico a indução, instalado em uma fundição de aços especiais, através das análises de confiabilidade do mesmo, Fagundes et al. (2011) aplicaram distribuições de probabilidade para analisar a sensibilidade da taxa de falha de um torno CNC com a sua estratégia de manutenção. Silva e Anzanello (2012) propuseram um ciclo (frequência) de manutenções preventivas em um processo de calandragem com o objetivo de diminuição de refugos.

O artigo apresenta a seguinte estruturação: (i) referencial teórico; (ii) descrição do campo de pesquisa; (iii) metodologia aplicada; (iv) levantamento e análise de dados; e (v) considerações finais.

\section{ESTUDOS DE CONFIABILIDADE EM MANUTENÇÃO}

Para Wireman (2005) e Igba et al (2013) a Manutenção Centrada em Confiabilidade (MCC) representa uma evolução da manutenção tradiciona e é uma forma de capturar as possíveis causas de tempo de inatividade e desempenho ruim, evitando falhas e atuando proativamente. Selvik e Aven (2011) observam que, além de reduzir os custos de manutenção, a MCC também aumenta a segurança e confiabilidade do equipamento/sistema. Rausand (1998) relata que a MCC pode estender a sua análise além do enfoque tradicional de falhas em equipamentos, para problemas de suporte logístico e gestão de peças sobressalentes.

A confiabilidade encontra-se ricamente presente na literatura como fator de suporte ao sucesso na Gestão da manutenção. Em alguns casos, sua presença é detectada na própria definição do que é Manutenção, conforme Kardec e Nascif (2012), os quais definem manutenção como a função que garante a disponibilidade dos equipamentos e instalações de modo a atender a um processo de produção e à preservação do meio ambiente, com confiabilidade, segurança e custos adequados.

Os professores Fogliatto e Ribeiro em seu livro "Confiabilidade e manutenção industrial" (2009), apontam como condição prévia indispensável para a efetividade da cultura da Manutenção Centrada na Confiabilidade, a disponibilidade e riqueza das informações.

Logo, torna-se imperioso a taxonomia e a geração de bancos de dados capazes de registrar e classificar as falhas ocorridas em um sistema produtivo, desta forma possibilitando estudos e análises da confiabilidade, as quais produzirão tomadas de decisão para o correto planejamento das atividades de manutenção. 


\section{FUNÇÕES DA CONFIABILIDADE EM MANUTENÇÃO}

Vários autores indicam como principais funções para estudos em confiabilidade as funções densidade da probabilidade de falha, $f(t)$, confiabilidade, $\mathrm{R}(\mathrm{t})$, densidade acumulada de falha, $\mathrm{F}(\mathrm{t})$, e taxa de falha, $\lambda(\mathrm{t})$ (BAPTISTA, 2016; CUNHA, VILLAS-BOAS, KAMINSKI, 2012; FOGLIATTO, RIBEIRO, 2009).

\section{Função Densidade da Probabilidade de Falha, $\mathrm{f}(\mathrm{t})$}

A função densidade da probabilidade de falha $f(t)$, retrata a variação da probabilidade de falhas por unidade de tempo. É representada graficamente por uma função de distribuição de probabilidade e matematicamente representada pela equação (1).

$$
f(t)=\frac{d F(t)}{d t}
$$

\section{Função Densidade Acumulada de Falha, F(t)}

A função densidade acumulada de falha $F(t)$, segundo Fogliatto e Ribeiro (2009), fornece a probabilidade da unidade falhar em um intervalo de tempo $(0, t)$. Essa função pode ser observada conforme a equação 2 , onde adota-se $t>0$.

$$
F(t)=\int_{0}^{t} f(t) d x
$$

\section{Função Confiabilidade, $\mathrm{R}(\mathrm{t})$}

A função confiabilidade $R(t)$, pode ser obtida como um complemento da função acumulada de falha $F(t)$, resultando a equação 3 . Ao considerar um cenário em que os componentes são testados, existem probabilidades de falhas e de sucessos. A função $R(t)$ é definida como a acumulação de sucesso no tempo, ou seja a probabilidade de que não existam falhas em um intervalo de tempo $(t)$ (FOGLIATTO e RIBEIRO, 2009).

$$
R(t)=1-F(t)
$$

\section{Função Taxa de Falha, $\lambda(\mathrm{t})$}

Segundo Baptista (2016), é a frequência com que ocorre as falhas em um período de tempo, medida pelo número de falhas para cada hora ou número de operações do sistema ou do componente. Ela é representada por $\lambda(t)$ e determinada pela equação abaixo. 


$$
\lambda=\frac{\text { Frequência de Falha em um período de tempo }}{\text { Número de Falhas }}
$$

\section{CAMPO DE PESQUISA}

O processo de refino da alumina, que é uma matéria prima indispensável para a fabricação do alumínio primário, é complexo e leva uma série de etapas que precisam ser muito bem ajustadas e controladas. Trata-se de um processo contínuo, onde qualquer falha no sistema pode provocar a parada parcial e/ou total de uma linha de produção. A seguir tem-se um resumo do contexto no qual se insere o equipamento estudado e a importância do mesmo para produção de alumina.

Na Figura 1, tem-se uma visão do processo como um todo da área de "precipitação" de uma refinaria de alumina, os primeiros tanques são responsáveis por aglomerarem cristais de hidrato dando maior volume ao produto, nos tanques subsequentes, verifica-se os cementadores, responsáveis pela resistência mecânica do produto, neles também são adicionadas partículas com granulometria menores provenientes do sistema de filtragem de sementes, essas partículas são responsáveis por aumentar a taxa de precipitação da cadeia. Por fim, observa-se os tanques de leito denso, responsáveis por aumentar o tempo de residência da cadeia, elevando a quantidade de hidrato precipitado.

Figura 1 - Visão geral do processo de precipitação

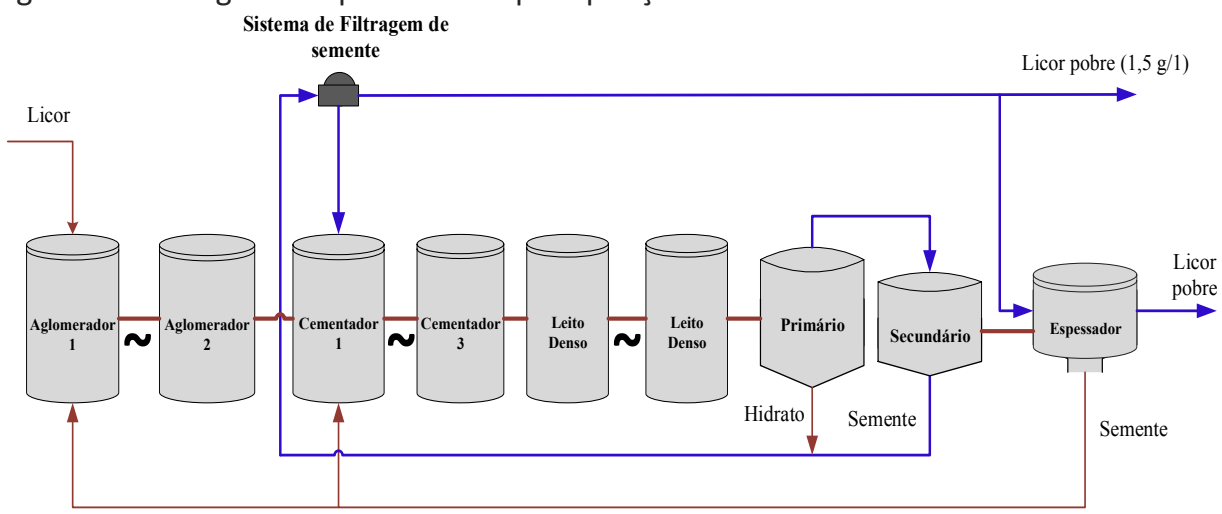

Fonte: Autoria própria (2018)

O sistema de filtragem de semente (em destaque na Figura 1), tem como alimentação a polpa de semente grossa (sólido + líquido) proveniente dos classificadores secundários, nesse sistema realiza-se a separação do sólido (hidrato) do líquido (licor pobre), o sólido é direcionado ao precipitador cementedor $n=1$, e o licor filtrado para os tanques de estocagem de licor pobre (Área-06) ou espessador.

Na Figura 2 observa-se a árvore dos componentes que formam o sistema de filtragem de semente grossa, onde é impossível identificar o posicionamento estratégico dos transportadores de correias para o sucesso das operações. 
Figura 2 - Árvore dos componentes

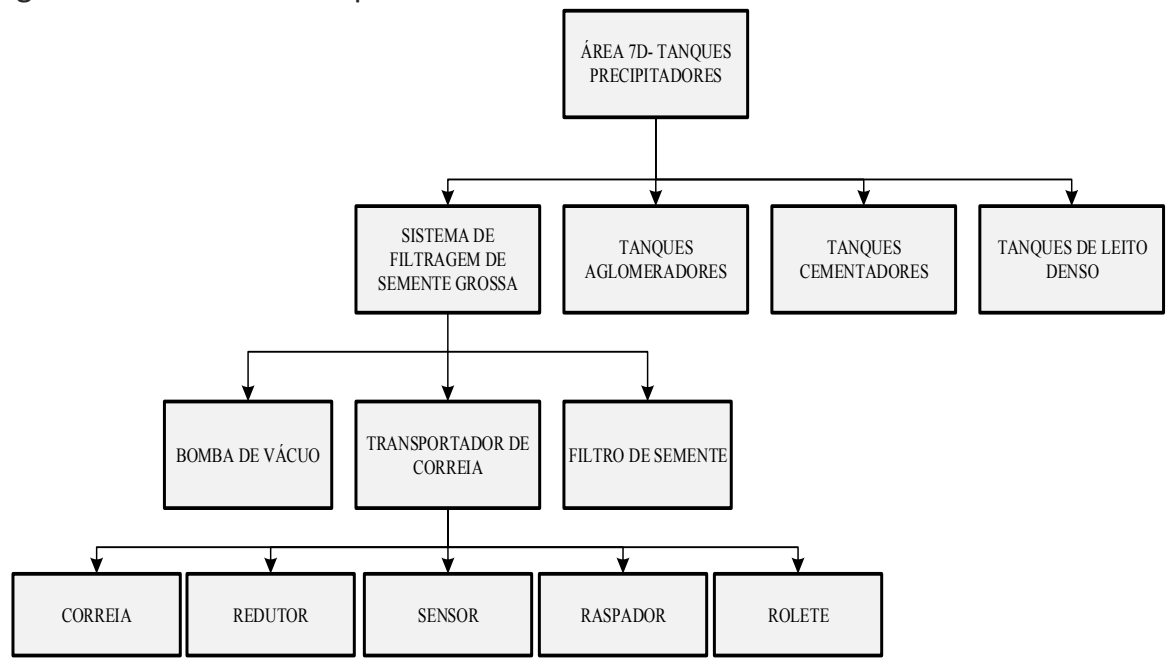

Fonte: Autoria própria (2018)

A área de filtração de Semente Grossa foi projetada para desempenhar as seguintes funções:

- Filtrar a polpa de Semente grossa deixando-a seca.

- Gerar filtrado com concentração de sólidos $<1,5 \mathrm{~g} / \mathrm{l}$.

O objetivo desse sistema é de reduzir a recirculação de licor pobre nas cadeias de precipitação, com impacto positivo no aumento da produtividade da precipitação e em consequência maior produção de hidrato para a mesma vazão de licor rico. Contribuir para a redução da vazão de recirculação de licor, reduzindo o arrasto de sólidos, ampliando o tempo de residência e diminuindo a alimentação dos secundários o que otimiza a eficiência de classificação do hidrato. Na Figura 3 observa-se a área da filtragem de semente grossa, tagueada no sistema interno de codificação da empresa, como área $48 \mathrm{~B}$.

Figura 3 - Vista da área 48 B

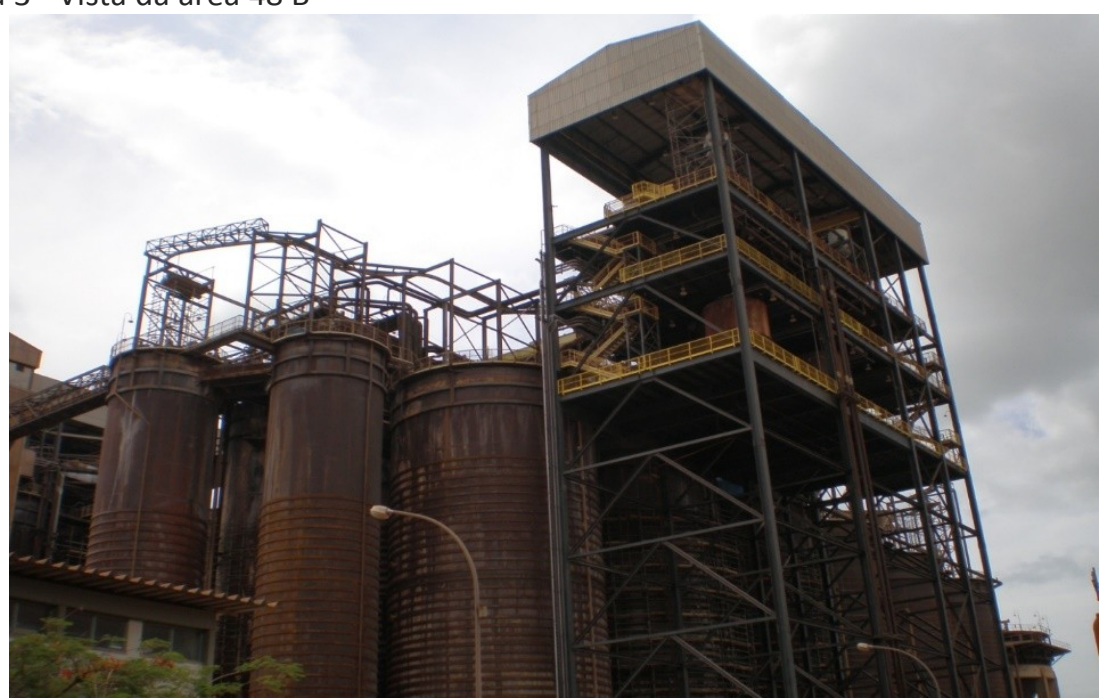

Fonte: Autoria própria (2018) 
O espessador de hidrato também se beneficia, uma vez que o licor filtrado é bombeado diretamente para os tanques de licor pobre da área 06 quando a concentração de sólidos no filtrado estiver menor que $1,5 \mathrm{~g} / \mathrm{l}$.

Outro benefício para o espessador é a redução na adição de floculante e a redução do próprio uso do espessador que deve funcionar em stand by, favorecendo a redução de custos.

O processo de descarga do hidrato seco é realizado através de transportadores de correia de hidrato. Esses equipamentos são críticos para o processo uma vez que sem ele não é possível realizar a alimentação dos tanques cementadores, levando a uma consequente perda de produção pelo fato de não existir semente para acelerar a precipitação de hidrato. Dessa forma, os transportadores tornam-se foco de estudo desse trabalho, objetivando implementar técnicas modernas de Engenharia de Manutenção para torná-lo confiável de maneira que reduza ao máximo as perdas de produção.

\section{METODOLOGIA}

A pesquisa desenvolvida pode se classificar como aplicada tendo em vista que seus procedimentos metodológicos estão voltados para desenvolvimento de soluções de problemas reais do departamento da empresa estudada (TURRIONI e MELLO, 2012).

Em relação à abordagem, a pesquisa tem o perfil quantitativo, pois considera que a falha pode ser quantificável, o que significa traduzir em números opiniões e informações para classificá-las e analisá-las. Para isso, esse tipo de abordagem requer o uso de recursos e de técnicas estatísticas (TURRIONI e MELLO, 2012; GIL, 2017).

Quanto aos seus objetivos, a pesquisa pode ser classificada em exploratória, descritiva, explicativa e normativa.

A pesquisa descritiva visa descrever as características de determinada população ou fenômeno ou o estabelecimento de relações entre variáveis. Envolve o uso de técnicas padronizadas de coleta de dados: questionário e observação sistemática (GIL, 2017). Assim, o artigo pode ser classificado como descritivo quantos aos seus objetivos, visto que faz o uso de coleta de dados através de observações diretas dos processos, assim como descreve as características dos principais processos envolvidos.

A metodologia do trabalho foi baseada em Miguel et al. (2010):

- Revisão bibliográfica dos conceitos de confiabilidade aplicados à manutenção de equipamentos industriais;

- Planejamento e delimitação do sistema a ser estudado: motoredutores de transportadores de correia da área de filtragem de semente grossa em uma refinaria de alumina, dada sua importância no processo de fabricação, levantando-se o histórico de falha dos transportadores de correia através do sistema integrado da empresa, em seguida montando-se gráficos de Paretos, assim, identificando os componentes com grande número de falhas, 
quando se revelou a necessidade dos estudos se concentrarem nos motoredutores;

- Obtenção dos dados dos tempos até o reparo dos motoredutores, considerando os eventos ondo houve a substituição dos mesmos por unidades novas ou reformadas em um centro de reparo, analisou-se o relatório de falhas dos anos de 2014, 2015 e 2016, acumulando assim três anos de histórico;

- Análise dos dados por modelagem pelas distribuições gamma, normal, lognormal, exponencial e Weibull, pelo software ProConf 2000;

- Definição da distribuição que melhor se ajusta aos dados com base nos testes de máxima verossimilhança e na premissa da pesquisa;

- Geração das funções densidade da probabilidade de falha, $f(t)$, densidade acumulada de falha, $F(t)$, confiabilidade, $R(t)$;

- Identificação do ponto no ciclo de vida em que o equipamento se encontra (função taxa de falha $\lambda(t))$; e

- Discussão dos resultados, análise da estratégia atual e proposta de estratégia de manutenção mais adequada aos motoredutores.

\section{ESTUDO DE CONFIABILIDADE}

Através dos gráficos de Pareto foi possível identificar as principais falhas do transportador de correia, que segundo estudo abaixo se trata da falha no motoredutor e o rasgo da correia. Sendo o sistema composto por 20 (vinte) transportadores de correias da área 48B, cada um equipado com um motoredutor KA87/T AM132S/M (figura 4), todos iguais em seu modelo e em sua aplicação, sendo ilustrado na Tabela 1 as principais características técnicas do mesmo.

Tabela 1 - Características técnicas do motoredutor KA87/T AM132S/M

\begin{tabular}{cc} 
Modelo & KA87/T AM132S/M \\
Voltagem (v) & 10 \\
Frequência (Hz) & 440 \\
Polos & 60 \\
Grau de proteção & 4 \\
Método de partida & IP $55 \mathrm{~W}$ \\
Redução & Direto \\
\hline
\end{tabular}

Fonte: Autoria própria (2018) 
Figura 4 - Motoredutor KA87/T AM132S/M instalado em uma dos transportadores de correia

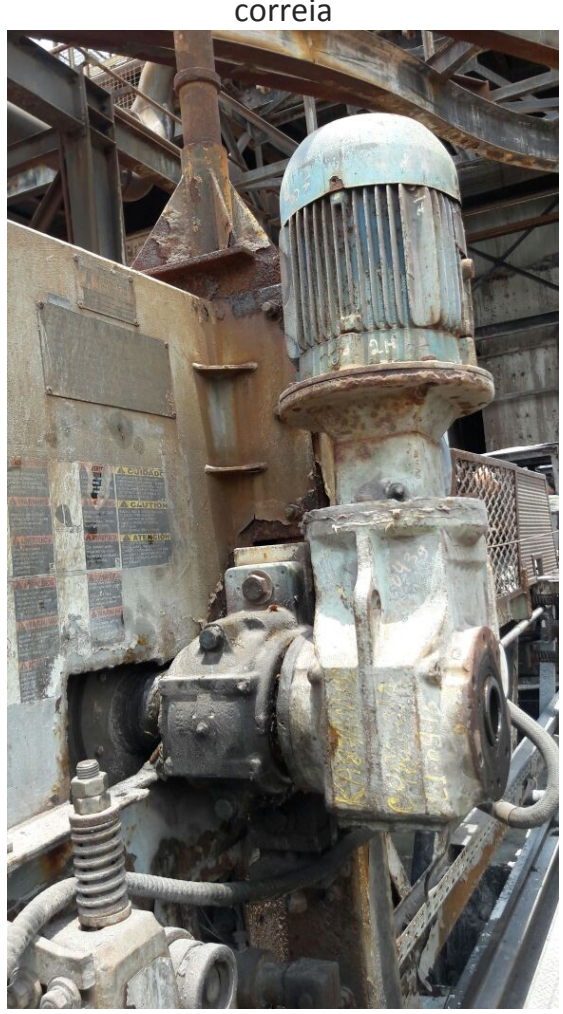

Fonte: Autoria própria (2018)

Nota-se no Gráfico 1, que a principal falha ocorrida nos transportadores de correia entre 2014 e 2016, consistiu na quebra dos motoredutores do seu acionamento e o rasgo do tapete da correia, daí, as análises de confiabilidade se concentraram na maior causa: quebra dos motoredutores KA87/T AM132S/M.

Gráfico 1- Falhas das correias da 48B

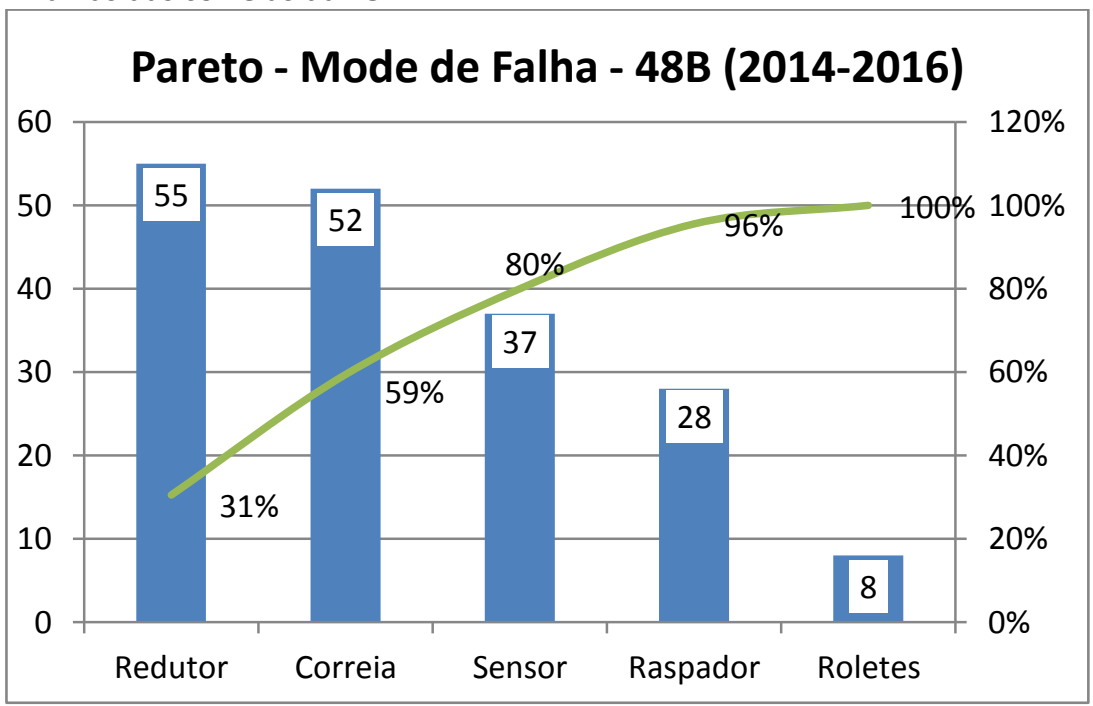

Fonte: Autoria própria (2018)

Retirou-se os tempos até a falha dos motoredutores dos transportadores de correia da área 48B, através do sistema de controle das operações, filtrando 
apenas os eventos em que houve a quebra do motoredutor, a qual levou a subsituição do mesmo por um novo, obtendo-se os dados listados na Tabela 2. As informações pertinentes às atividades de manutenção são registradas no sistema de informação da empresa, fonte dos dados contidos na Tabela 2.

Tabela 2-Tempo em horas até a falha do motoredutor

\begin{tabular}{|c|c|c|c|c|c|c|c|}
\hline Ordem & $\begin{array}{c}\text { Tempo } \\
\text { (h) }\end{array}$ & Ordem & $\begin{array}{c}\text { Tempo } \\
\text { (h) }\end{array}$ & Ordem & $\begin{array}{c}\text { Tempo } \\
\text { (h) }\end{array}$ & Ordem & $\begin{array}{c}\text { Tempo } \\
\text { (h) }\end{array}$ \\
\hline 1 & 24 & 11 & 96 & 21 & 432 & 31 & 792 \\
\hline 2 & 24 & 12 & 120 & 22 & 456 & 32 & 840 \\
\hline 3 & 24 & 13 & 144 & 23 & 456 & 33 & 912 \\
\hline 4 & 24 & 14 & 144 & 24 & 504 & 34 & 1008 \\
\hline 5 & 24 & 15 & 168 & 25 & 528 & 35 & 1248 \\
\hline 6 & 72 & 16 & 192 & 26 & 576 & 36 & 1704 \\
\hline 7 & 72 & 17 & 192 & 27 & 600 & 37 & 1848 \\
\hline 8 & 96 & 18 & 264 & 28 & 624 & 38 & 2304 \\
\hline 9 & 96 & 19 & 264 & 29 & 672 & 39 & 3096 \\
\hline 10 & 96 & 20 & 408 & 30 & 696 & 40 & 3696 \\
\hline
\end{tabular}

Fonte: Autoria própria (2018)

Para o estudo de confiabilidade, utiliza-se do software ProConf 200, tal aplicativo faz uso de métodos analíticos e gráficos para ajustar amostras de tempos de falha e de reparo a distribuições de probabilidade, o software testa o ajuste dos dados aos seguintes modelos paramétricos: exponencial negativa, gamma, normal, lognormal e Weibull (CERVEIRA E SELLITTO, 2015).

Os parâmetros da distribuição são calculados por máxima verossimilhança pelos testes de Qui-Quadrado $\left(\chi^{2}\right)$ e Kolmogorov-Smirnov (KS) (FRITSCH;RIBEIRO, 1998). Para cada teste, o software informa o nível de significância e aponta que distribuições não podem ser rejeitadas. A validação é dada se o nível de significância for maior que $5 \%$ em ambos os testes (CERVEIRA E SELLITTO, 2015).

Informações complementares sobre o ProConf 2000 e suas rotinas são encontradas em Fritsch e Ribeiro (1998). Mais considerações sobre o teste de máxima verossimilhança podem ser encontradas em Lawless (2003), e melhoramentos do seu uso no modelo de Weibull em Ho e Silva (2005).

Os dados de tempo até o reparo dos motoredutores foram testados para as distribuições: (i) exponencial, (ii) gamma, (iii) normal, (iv) lognormal e (v) Weibull, testes suportados pelo software ProConf 2000.

A Tabela 3, apresenta os resultados dos testes de aderência, a hipótese de que os dados se ajustem às distribuições Weibull, Gamma e Lognormal não podem ser rejeitadas. Pela premissa da pesquisa, adotou-se o modelo Weibull.

Tabela 3-Testes de aderência

\begin{tabular}{cccc} 
Distribuição & Teste $x^{2}$ & Teste KS & Decisão \\
Weibull & $60,82 \%$ & $29,98 \%$ & Não rejeitada \\
Gamma & $57,63 \%$ & $26,92 \%$ & Não rejeitada \\
Lognormal & $43,11 \%$ & $7,58 \%$ & Não rejeitada \\
Exponencial & $25,23 \%$ & $1,30 \%$ & Rejeitada \\
\hline
\end{tabular}




\begin{tabular}{cccc}
\hline Normal & $0,01 \%$ & $0,01 \%$ & Rejeitada \\
\hline Fonte: Autoria própria (2018) & &
\end{tabular}

O ProConf 2000 oferece uma análise gráfica, intitulada no softaware como "papel de probabilidade", apresentada na Figura 5, percebe-se que o modelo Weibull descreve satifatoriamente a amostra de dados acerca as falhas do motoredutor, assim, ratificando os resultados analíticos da Tabela 3.

Figura 5 - Papel de probabilidade para distribuição de Weibull

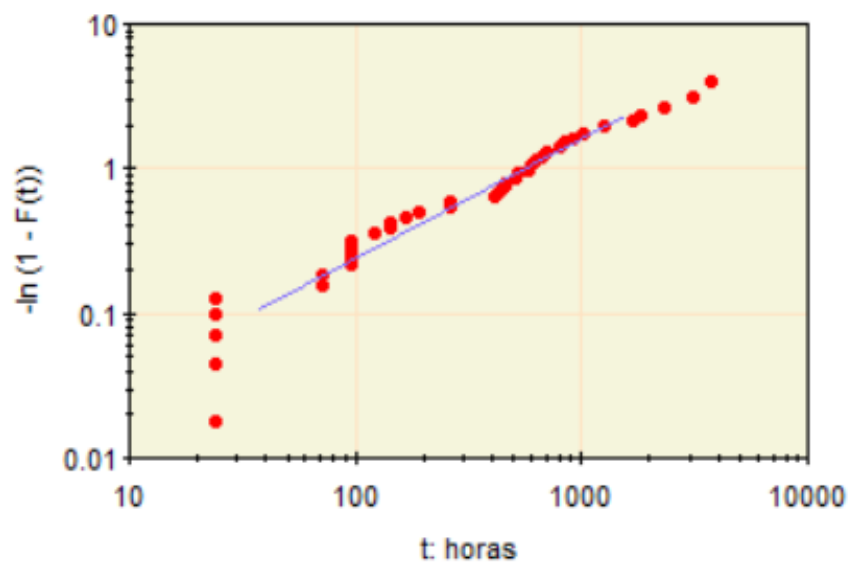

Fonte: Autoria própria (2018)

Os resultados dos ajustes/estatisticas apresentados pelo ProConf 2000 são indicados na Tabela 4. O tempo médio até o reparo ou MTTF (do inglês Mean Time to Failure) do motoredutor é de 648,98 horas. Os valores de t10 e t50 que consistem nos limites de tempos em que $10 \%$ e $50 \%$ dos reparos ocorreram, ficaram em 31,71 horas e 352,58 horas, respectivamente. Para um intervalo de confiança de $95 \%$, o tempo médio até o reparo (MTTF) compreende valores entre 356,15 a 867,04 horas.

Tabela 4-Resultados dos ajustes/estatísticas

\begin{tabular}{cc} 
Parâmetro & Resultado \\
$t_{10}$ & 31,71 \\
$t_{50}$ & 352,58 \\
MTTF & 648,98 \\
IC $95 \%$ & 356,15 a 867,04 \\
\hline
\end{tabular}

Fonte: Autoria própria (2018)

A seguir apresenta-se as curvas da Confiabilidade (Figura 6), Densidade acumulada de falha (Figura 7), Densidade de probabilidade de falha (Figura 8) e Taxa de falha (Figura 9), para diferentes intervalos de tempo. 
Figura 6-Função Confiabilidade R(t)

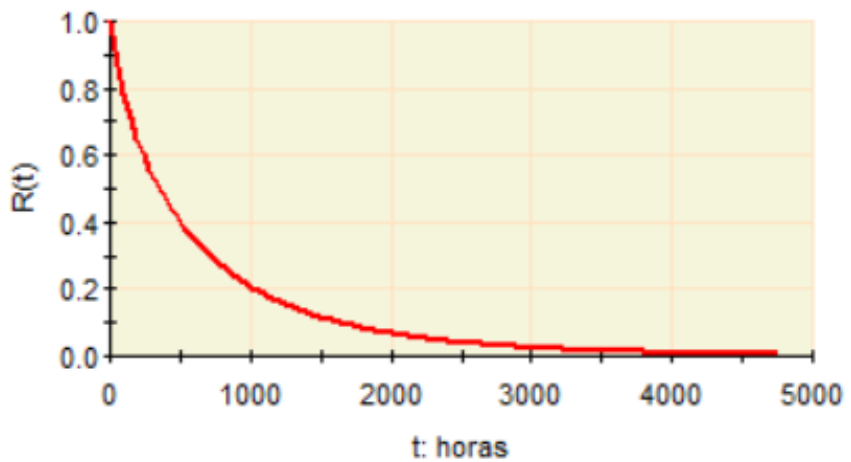

Fonte: Autoria própria (2018)

Figura 7-Função Densidade acumulada de falha $F(t)$

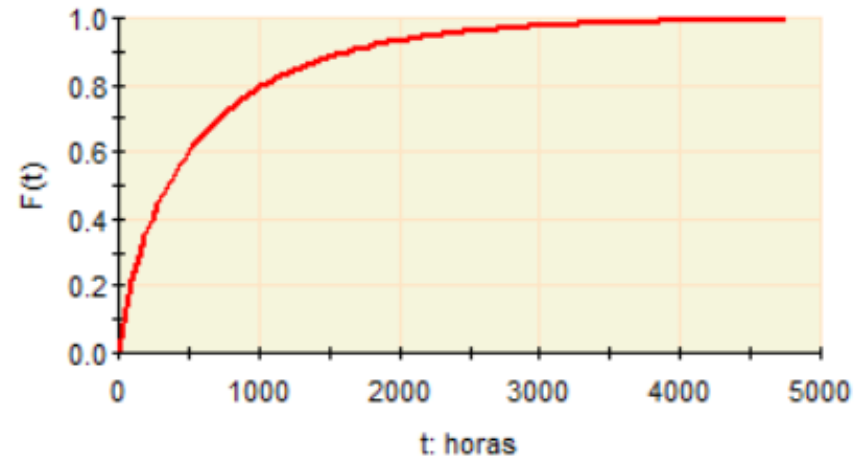

Fonte: Autoria própria (2018)

Figura 8-Função Densidade da probabilidade de falha $f(t)$

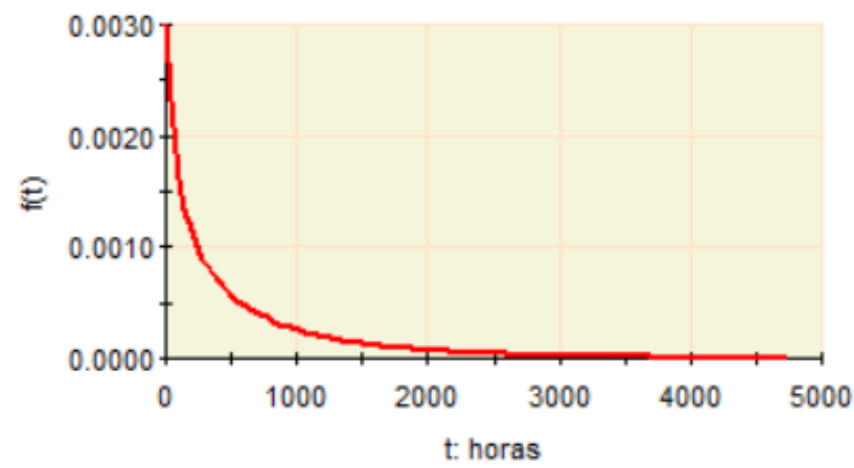

Fonte: Autoria própria (2018) 
Figura 9-Função Taxa de falha $\lambda(t)$

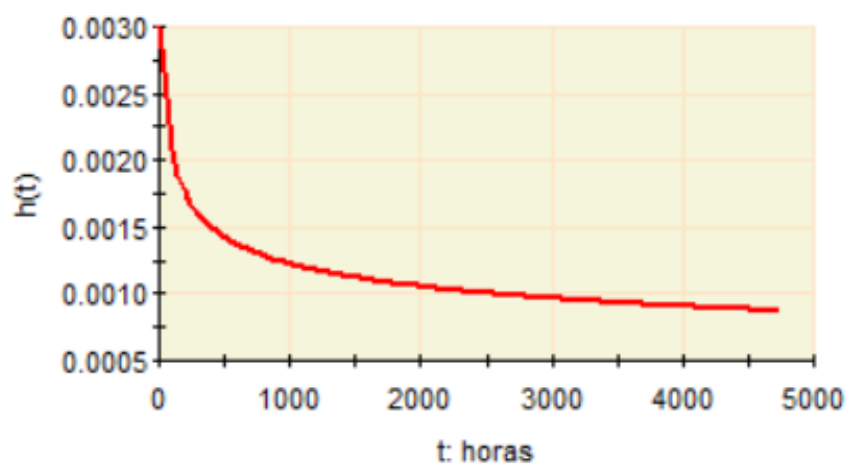

Fonte: Autoria própria (2018)

Avaliando a taxa de falha, $\lambda(t)$ ou função de risco, $h(t)$, como também é chamada, verifica-se a quebra do motoredutor que leva a sua substituição, tem um comportamento considerado como "mortalidade infantil", uma vez que existe uma alta taxa de falha no início de operação reduzindo a medida que o equipamento consegue operar sem falhas. Além disso, pela equação de Weibul, o parâmetro de forma ( $\gamma$ ) é menor que 1.

Observando a Tabela 4, percebe-se um MTTF bastante aquém da necessidade da área, visto que um valor de 648,98 horas, em uma planta que opera 7 (sete) dias por semana e 24 (vinte e quatro horas) ao dia, tem-se uma quebra com substituição do motoredutor de transportador de correias a cada 27 dias, ou seja, todo mês um evento deste porte acontece. Podendo ser pior, uma vez que em $50 \%$ dos eventos se apresentam no limite de 352,58 horas, ou seja, a cada 15 dias de operação.

A estratégia de manutenção sobre tais motoredutores baseia-se em inspeção preditiva, através de análise de vibrações coletadas mensalmente e planos de lubrificação a cada 36 semanas.

Percebe-se que os modos de falhas dos motoredutores necessitam ser melhor compreendidos, visto os equipamentos que obedecem a curva da banheira em seu comportamento, têm característica aleatória, causados por falhas de operação, usos incompatíveis, instalação modificada ou por falhas na execução de procedimentos (SELLITTO, 2005).

Observando as informações de falhas do sistema de informação da empresa, as causas que mais levaram a quebra do motoredutor KA87/T AM132S/M foram relacionadas a desgastes no seu eixo de entrada e quebras de engrenamento devido a insuficiência na lubrificação, ao observar mais detalhadamente, que ambas as causas repousavam em um fato comum: deficiência na vedação do eixo de entrada do motoredutor.

As análises em campo revelaram que a totalidade dos motoredutores apresentavam um retentor adaptado em seu conjunto de vedação, tal adaptação apresentava um anel metálico em contato com o eixo, no sentido de compensar o diâmetro menor do retentor em relação a peça original, o que induzia o desgaste prematuro no eixo de entrada.

A busca de informações sobre a motivação para tal adaptação revelou um outro fato interessante, na época em que havia a utilização do conjunto de 
vedação original, a incidência de vazamentos era acima do normal, acarretando assim em quebras, sendo a adaptação do anel metálico uma tentativa de melhoria no cenário, informações estas prestadas por técnicos mais antigos da área.

A análise sobre o motoredutor KA87/T AM132S/M, além do aprendizado nas ferramentas da engenharia da confiabilidade, a necessidade de revisão dos processos de manutenção no que tange a: (i) monitoramento das condições e (ii) modificações e melhorias.

De acordo com Baptista (2016) o monitoramento das condições pode ser dividido em dois grupos: monitoramento subjetivo e objetivos. O primeiro é realizado de forma sensitiva, ou seja, visão, audição, tato e olfato de uma pessoa que detenha habilidades no processo de manutenção. A segunda forma de monitoria é aquela em que necessita de instrumentos de medição, para avaliar algum parâmetro em específico. Alguns testes realizados nesse tipo de monitoramento são: análise de vibração, ultrassom, verificação de óleo, temperatura, raio $x$, etc.

O processo de "Modificações e Melhoria" estabelece uma forte ligação com os demais processos do macroprocesso da manutenção, onde fornece subsídios para a busca da eficiência nas plantas industriais, bem como a análise e busca constante de melhores práticas empresariais. É comum as empresas a existência de perdas e falhas durante seu funcionamento, entretanto o que precisa ser estudado é a gravidade e a frequência, com o objetivo na redução ou eliminação das mesmas. Um processo coerente a essa situação é o critério de "Tratamento de falhas e perdas" que aborda quais serão os quesitos ou planos de decisão a serem efetuados mediante a deteç̧ão de um problema. Nessa etapa identifica-se os melhores procedimentos e técnicas para corrigir o problema.

Uma vez que os motoredutores KA87/T AM132S/M constituem-se em equipamentos críticos para a área da filtragem da semente grossa, por conseguinte, de todo o processo de refino de alumina, o time de Manutenção da empresa pode adotar a metodologia da Manutenção Centrada na Confiabilidade (MCC), o qual possibilita a adequada análise dos modos de falha do equipamento, observando e influenciando positivamente no macroprocesso da manutenção, inclusive em seus processos de "monitoramento das condições" e "modificações e melhorias" em ativos físicos.

A Manutenção Centrada em Confiabilidade (MCC), consiste em um processo usado para determinar os requisitos de manutenção de qualquer item físico no seu contexto operacional (MOUBRAY, 1997). Esta técnica visa estudar as diversas formas de como um componente pode vir a falhar, visualizando através disto as ações de bloqueios pertinentes a serem tomadas. Na verdade, a MCC se coloca como um importante instrumento para tomada de decisão gerencial, sobre quais as diretrizes da política de manutenção a serem seguidas por um processo industrial (VIANA, 2002).

O primeiro passo para procedermos à implantação de um trabalho baseado na MCC, é a seleção de um sistema operacional, no caso deste artigo, o motoredutor KA87/T AM132S/M. O passo seguinte é a formação da equipe de $\mathrm{MCC}$, onde deverá se fazer presente um representante, de cada área que tenha influência sobre o desempenho do motoredutor KA87/T AM132S/M, sendo coordenados por um facilitador que possua um excelente conhecimento na 
técnica do MCC, pois do mesmo dependerá o sucesso do empreendimento, é ele que orientará a equipe na aplicação correta da filosofia da MCC, organizará o escopo dos trabalhos, de forma a abranger todos os equipamentos pertinentes, presidirá todas as reuniões da equipe primando pelo caminho da objetividade e foco no resultado, e por fim, reunirá todas as informações levantadas e acordadas em uma única documentação, que se constituirá como sendo o trabalho final da revisão MCC.

A equipe de $\mathrm{MCC}$, como já foi dito, será formada por representantes de cada área que influencia o desempenho do motoredutor KA87/T AM132S/M, isto se dar devido ao fato de tanto as perguntas, como também as respostas sobre os itens, não serem de domínio completo de uma só pessoa, há coisas que só o mantenedor se atém, por outro lado, também existem questões de domínio exclusivo do operador, deste modo a reunião destes vários pontos de vista de um mesmo equipamento, enriquece de sobremaneira a sua avaliação por completo, evitando assim que importantes nuanças sejam esquecidas (VIANA, 2002).

A utilização da Manutenção Centrada em Confiabilidade (MCC), pode resultar na redução das atividades de manutenção preventiva e seus respectivos custos. A MCC é um processo contínuo e sua aplicação deve ser periodicamente reavaliada (CERVEIRA; SELLITTO,2015).

Observando-se o caso concreto do motoredutor KA87/T AM132S/M notouse a necessidade de alteração da abordagem sobre os equipamentos críticos da organização, sendo indicada a aplicação da Manutenção Centrada em Confiabilidade nos mesmos, de maneira a possibilitar planos de manutenção pertinentes às demandas do equipamento, bem como, analisar características do seu projeto original que possam contribuir para uma possível perda em confiabilidade.

\section{CONCLUSÃO}

O objetivo deste artigo foi analisar a confiabilidade dos motoredutores KA87/T AM132S/ dos transportadores de correias da área de filtração de semente fina e grossa de uma refinaria de alumina. Através do estudo realizado verificou-se um grande gargalo e oportunidade para aumento do desempenho dos transportadores de correias, através da melhoria da confiabilidade dos motoredutores KA87/T AM132S/M, que foram responsáveis por $59 \%$ das falhas no período de 2014-2016.

Foram revisados os conceitos de confiabilidade, onde foram revisadas as funções densidade, densidade acumulada de falhas, confiabilidade e risco.

Através da análise de taxa de falha, observou-se que a curva a qual responde o motoredutor estudado é da "banheira", permitindo concluir que se têm sérios problemas nas intervenções em campo, incorporando defeitos desde a partida que levam a uma acelerada quebra de seus componentes, principalmente motoredutores, além disto, nota-se um desafio em torno do sistema de vedação do motoredutor, onde cabe uma reavaliação do seu projeto, buscando a interrupção da ocorrência de falhas decorrente de contaminações e vazamentos severos de óleo lubrificante em todos os vinte motoredutores analisados. 
Foram levantados do sistema de informação da empresa, dados de tempos até a falha do equipamento (motoredutor), considerando apenas as intervenções onde houve a troca do motoredutor por um novo. Os dados foram analisados com o auxílio do software ProConf 2000. Assumiu-se que os dados coletados fossem confiáveis.

Ressalte-se a importância deste estudo para empresa, uma vez que a área de filtragem de semente grossa é gargalo no processo industrial, e decorrente disto, os transportadores de correia que a compõem ocupam lugar de destaque na estratégia de produção da planta, acarretando assim a importância em elevar a confiabilidade dos acionamentos de tais transportadores, no caso, dos motoredutores KA87/T AM132S/M.

Conclui-se que análises quantitativas dos tempos até a falha (MTTF), podem ser importantes na definição da estratégia de manutenção da empresa, pois apresentam aos gestores da empresa visualizarem o reflexo das ações de manutenção na confiabilidade do sistema.

Por fim, para trabalhos futuros com intuito de continuidade da pesquisa, sugere-se, o desenvolvimento de FMEA para os transportadores de correia, identificando as causas raízes dos problemas de rasgo de correia e quebra de motoredutor, verificando-se os métodos de controles atuais e sugerindo novos métodos através da revisão dos planos de manutenções. 


\title{
Reliability-related maintenance: application in motoreducers of belt conveyors in an aluminum refinery
}

\begin{abstract}
This work presents an application of the Reliability study through data analysis and curve generation $R(t), F(t), f(t)$ e $\lambda(t)$, considering its use in the operational base of the hydrate filtration area of an alumina refinery. The main objective is found the degree of reliability of the gearmotor model KA87/T AM132S/M, used in the drive of belt conveyors of the hydrate filtration system. The reliability study was done using the software Proconf 2000Through the adhesion tests, we see that the distribution of Weibull satiately describes the data sample, with values of $\chi 2$ with seignificance level of $60,82 \%$, and with a Kolmogorov-Smirnov (K-S) test of $30 \%$. Mean time to repair is 648,98 hours. The values of t10 and t50 were at 31.71 hours and 352.58 hours, respectively. For a $95 \%$ confidence interval, the mean time to repair (MTTF) ranges from 356.15 to 867.04 hours, it was also verified that the response rate corresponds to the tub curve. The main failure originated due to leakage by shaft sealing system, finally, it is recommended the application of the application of Reliability Centered Maintenance (RCM) for critical plant equipment.
\end{abstract}

KEYWORDS: Reliability. Alumina refinery. Maintenance. 


\section{REFERÊNCIAS}

AL-TURKI, U. A framework for strategic planning in maintenance. Journal of Quality in Maintenance Engineering, v. 17, n. 2, p. 150-162, 2011. crossref

ASSOCIAÇÃO BRASILEIRA DE NORMAS TÉCNICAS-ABNT. NBR 5462: confiabilidade e mantenabilidade. Rio de Janeiro, 1994.

BAPTISTA, J. A. Manutenção industrial: Técnicas, contos e causos. São Paulo: Lura editorial, 2016.

CERVEIRA, D. S.; SELLITTO, M. A. Manutenção Centrada em Confiabilidade (MCC): análise quantitativa de um forno elétrico a indução. Revista Produção Online, Florianópolis, v.15, n. 2, p. 405-432. abr./jun. 2015. crossref

CUNHA, M.; VILLAS-BOAS, F.; KAMINSKI, P. Considerações sobre Confiabilidade no Projeto de Submarinos. Produto \& Produção, v.13 n.1, p.114-130, 2012.

FAGUNDES, A. et al. Estudo de caso: análise quantitativa de confiabilidade e disponibilidade de um torno CNC, baseado na metodologia RCM (Reliability Centred Maintenance), aplicado a área de manutenção industrial. Anais do XXXI ENEGEP, Encontro Nacional de Engenharia de Produção. Belo Horizonte: ABEPRO, 2011.

FOGLIATTO, F. S.; RIBEIRO, J. L. D. Confiabilidade e manutenção industrial. Rio de Janeiro: Elsevier, 2009.

FRITSCH, C.; RIBEIRO, J. PROCONF: Um software orientado para análises de confiabilidade. In: ENCONTRO NACIONAL DE ENGENHARIA DE PRODUÇÃO ENEGEP, 1998, Niterói. Anais... Niterói: ABEPRO, 1998.

GIL, A. C. Como elaborar projetos de pesquisa. 6. ed. São Paulo: Atlas, 2017.

HO, L.; SILVA, A. Estimadores não viciados para o tempo médio até a falha e para percentis obtidos do modelo de regressão Weibull. Gestão \& Produção, v.12, n.1, p.97-105, 2005. http://dx.doi.org/10.1590/S0104-530X2005000100009. crossref

IGBA , J. et al. A Systems Approach Towards Reliability-Centred Maintenance (RCM) of Wind Turbines. Procedia Computer Science, v. 16, p. 814-823, 2013. crossref 
KARDEC, A.; NASCIF, J. Manutenção: Função Estratégica. 4 ed. Rio de Janeiro:

Qualitymark, 2012.

LAWLESS, J. Statistical models and methods for lifetime data. New York: John Wiley \& Sons, 2003.

MIGUEL, P. A. C. et. al. Metodologia de pesquisa em engenharia de produção e gestão de operações. Rio de Janeiro: Elsevier, 2010.

MOUBRAY, J. Reliability-centred Maintenance. 2 ed. New York: Industrial Press. 1997. $426 \mathrm{p}$.

NASCIF, J. Manutenção de Classe Mundial. Revista Manutenção e Qualidade, São Paulo, n.29, p. 8. 2000.

OTANI, M.; MACHADO, W. V. A proposta de desenvolvimento de gestão da manutenção industrial na busca da excelência ou classe mundial. Revista Gestão Industrial, Campus Ponta Grossa, v. 4, n. 2, 2008.

RAUSAND, M. Reliability Centered Maintenance. Reliability Engineering and System Safety, v. 60, p. 121-132, 1998. crossref

RAZA, T.; MUHAMMAD, M. B.; MAJID, M. A. A. A comprehensive framework and key performance indicators for maintenance performance measurement. ARPN Journal of Engineering and Applied Sciences, v. 11, n. 20, p. 12146-12152, 2016.

SALONEN, A.; BENGTSSON, M. The potential in strategic maintenance development. Journal of Quality in Maintenance Engineering, v. 17, n. 4, p. 337350,2011 . crossref

SELLITTO, M. Formulação Estratégica da Manutenção Industrial com base na Confiabilidade dos Equipamentos. Revista Produção, Santa Catarina, v.15, n.1, p. 44-59, 2005. crossref

SELVIK, J. T; AVEN, T. A framework for reliability and risk centered maintenance. Reliability Engineering and System Safety, v. 96, n. 2, p. 324-331, 2011. crossref

SILVA, A.; ANZANELLO, M. Análise de confiabilidade para a redução do índice de refugo em um processo de calandragem. Trabalho de Conclusão de Curso (Graduação em Engenharia de Produção) - Universidade Federal do Rio Grande do Sul, Porto Alegre: 2012. 
TURRIONI, J. B.; MELLO, C. H. P. Metodologia de pesquisa em engenharia de produção: estratégias, métodos e técnicas para condução de pesquisas quantitativas e qualitativas. Itajubá: UNIFEI, 2012.

VIANA, H. R. G. PCM: Planejamento e Controle da Manutenção. Rio de Janeiro: Qualitymark, 2002. 192p.

WIREMAN, T. Developing performance indicators for managing maintenance. New York: Industrial Press, 2005.

ZAIONS, D. R. Consolidação da metodologia de Manutenção Centrada em Confiabilidade em uma planta de Celulose e Papel. Dissertação (Mestrado em Engenharia de Produção) - Universidade Federal do Rio Grande do Sul, Porto Alegre, 2003.

Como citar:

VIANA, H. R. G.; MARQUES, A.; BIRANI, S.; SENA, S.; NOBUMASA, G. H. Manutenção centrada em

confiabilidade: aplicação em motoredutores de transportadores de correias em uma refinaria de alumina. $\mathbf{R}$.

Gest. Industr., Ponta Grossa, v. 14, n. 2, p. 186-205, abr./jun. 2018. Disponível em:

<https://periodicos.utfpr.edu.br/rgi>. Acesso em: XXX

Correspondência:

Herbert Ricardo Garcia Viana

Rua Desembargador Tulio Bezerra de Melo, 3700, Ap.201, Candelária, Natal, Brasil.

Direito autoral: Este artigo está licenciado sob os termos da Licença Creative Commons-Atribuição 4.0 Internacional.

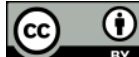

